\title{
STRUKTUR KOMUNITAS HUTAN MANGROVE DI DESA BUDO KECAMATAN WORI KABUPATEN MINAHASA UTARA
}

\author{
(Mangrove Community Structure at Budo Village Wori District North \\ Minahasa Regency)
}

\author{
Sarifudin Tidore ${ }^{1}$, Calvyn. F. A. Sondak ${ }^{1}$, Antonius P. Rumengan ${ }^{1}$ Erly Y. Kaligis ${ }^{1}$ \\ Elvy Like Ginting ${ }^{1}$ Christine Kondoy ${ }^{2}$ \\ ${ }^{1}$ PS IImu Kelautan Fakultas Perikanan dan Ilmu Kelautan UNSRAT \\ 2PS Manajemen Sumber Daya Perairan Fakultas Perikanan dan IImu Kelautan \\ UNSRAT \\ *e-mail: sarifudinti@gmail.com
}

\begin{abstract}
Mangrove forest can grow on the muddy soil, along the coast and around the river estuaries that are affected by the tidal. The mangrove forest has a specific vegetation structure. Study on the structure of the mangrove forest community, was carried out in the Budo Village. Mangrove community structure data was taken using line transect method. A $100 \mathrm{~m}$ line was established from the sea perpendicular to the coast. A total of three line transects was made and each line has five $10 \times 10 \mathrm{~m}$ plots with $20 \mathrm{~m}$ distance between plots. Distance between transect is $50 \mathrm{~m}$. This study found that three mangrove species Rhizophora apiculata, Sonneratia alba, and Bruguiera gymmorrhiza were found in the three transects during this study. The highest species biodiversity index was found in transect two $\left(H^{\prime}=0.97\right)$. R. apiculata has the highest density and relative density $0.05 \mathrm{ind} / \mathrm{m}^{2}$ and $67.57 \%$. Both $R$. apiculata and $S$. alba have the highest frequency and relative frequency of 1.00 and $50 \%$ respectively. The highest species coverage and relative coverage area is belonging to $S$. alba in transect two, 25,89 and $63.57 \%$. S. alba has the highest Important value index 140.72 in transect two.
\end{abstract}

Keywords: Budo Village, Mangrove Forest, Community Structure.

\begin{abstract}
Abstrak
Mangrove adalah vegetasi hutan yang tumbuh pada tanah berlumpur, di daerah pantai dan sekitar muara sungai yang dipengaruhi oleh arus pasang surut air laut. Hutan mangrove memiliki struktur vegetasi yang khas, dan umumnya mirip pada setiap lokasi perairan pantai yang ditempati hutan mangrove. Penelitian struktur komunitas hutan mangrove, dilaksanakan di Desa Budo. Pengambilan data struktur komunitas mangrove menggunakan metode garis transek (line transect method) dengan cara, menarik garis lurus dari arah laut mangrove terluar menuju ke arah darat sepanjang $100 \mathrm{~m}$ hutan mangrove, hingga berbatasan dengan garis pantai. Kemudian dibuat 1 stasiun yang dimana 1 stasiun memiliki 3 Transek garis kuadran dengan 5 plot atau petak yang berukuran $10 \times 10 \mathrm{~m}^{2}$ dengan jarak antar plot sekitar $20 \mathrm{~m}$. Sedangkan jarak antar transect 1,2 dan 3 masing-masing $50 \mathrm{~m}$. Dari hasil penelitian yang dilakukan pada 3 stasiun, ditemukan 3 jenis mangrove yaitu: Rhizophora apiculata, Sonneratia alba, dan Bruguiera gymnorrhiza. yang termasuk dalam tiga famili Rhizophoraceae, Sonneratiaceae dan Bruguieraceae Adapun nilai tertinggi dari Indeks Keanekaragaman Jenis terdapat pada Transek 2 yaitu H' 0,97 . Sedangkan nilai Kerapatan Jenis dan Kerapatan relatif jenis tertinggi $0,05 \mathrm{ind} / \mathrm{m}^{2}$ dan $67.57 \%$ oleh $R$. apiculata pada transek 1 dan 3 . Untuk Frekuensi Jenis pada transek 1,2 dan 3 nilai tertinggi oleh $R$. apiculata dan $S$. alba yaitu 1,00 dengan Frekuensi Relatif Jenis $50,00 \%$ dimiliki oleh $R$. apiculata pada transek 1 . Untuk Tutupan Jenis nilai tertinggi dimiliki oleh $S$. alba yaitu 25,89 pada transek 2 dengan Tutupan Relatif Jenis yaitu $63,57 \%$ pada transek 2 yang merupakan jenis dengan pohon yang besar. Untuk Indek Nilai Penting tertinggi dimiliki oleh S. alba dengan nilai 140,72 terdapat pada transek 2.
\end{abstract}

Kata Kunci : Desa Budo, Struktur Komunitas, Hutan Mangrove. 


\section{Pendahuluan}

Indonesia merupakan negara yang memiliki mangrove terluas di dunia. Pada tahun 2010 diperkirakan luas mangrove di Indonesia 3,489,140 ha atau $23 \%$ dari luas hutan mangrove di dunia (Giri dkk., 2011). Mangrove adalah kelompok tumbuhan yang dapat tumbuh dengan baik pada kawasan pasang surut di daerah tropis dan subtropis (LIPI, 2014). Ekosistem mangrove sebagai satu kesatuan ekologis dapat ditinjau dari sudut komposisi flora dan fauna serta faktorfaktor lingkungan yang mempengaruhi keberadaannya (Kusen dkk., 2016).

Ekosistem mangrove di Indonesia umumnya terpencar-pencar dalam kelompok-kelompok kecil, sebagian besar ditemukan di Papua. Mangrove di Jawa, Sumatra, Sulawesi, Kalimantan dan Papua sudah terpengaruh kegiatan pembangunan, sedangkan di Maluku dan Nusa Tenggara relatif masih alami (Setyawa dkk., 2003 dalam Hayati, 2016). Pertumbuhan ekosistem vegetasi mangrove secara umum mengikuti suatu pola zonasi berkaitan erat dengan faktor lingkungan seperti tipe tanah (lumpur, pasir atau gambut), keterbukaan terhadap hempasan gelombang, salinitas, serta pengaruh pasang surut. (Dahuri, 2003).

\section{Ekosistem mangrove} merupakan salah satu ekosistem wilayah pesisir yang sangat potensial sebagai penyedia unsur hara bagi ekosistem mangrove dan wilayah perairan sekitarnya (Haris dkk., 2012; Rumengan dkk., 2018). Ekosistem mangrove berperan untuk melindungi daerah pantai dan biota yang berasosiasi, serta dapat memelihara keanekaragaman hayati. Beberapa penelitian yang berhubungan dengan ekosistem mangrove di Kecamatan Wori sebelumnya telah dilakukan oleh
Sondak (2015), Sapsuha dkk. (2018); Takarendehan $d k k$. (2018); Tidore $d k k$., (2018); Upara dkk., (2021).

Pentingnya penelitian ini dilakukan untuk mengetahui struktur komunitas mangrove dan kelimpahan jenisnya, distribusi serta hubungan tumbuhan mangrove dengan faktor lingkungan. Hal ini disebabkan dengan pengetahuan masyarakat tentang peranan ekosistem mangrove masih sangat terbatas, sesuai dengan kegiatan penanaman mangrove yang telah dilakukan oleh masyarakat. Tujuan dari penelitian ini yaitu untuk menganalisa struktur komunitas vegetasi mangrove di Desa Budo, Kecamatan Wori, Kabupaten Minahasa Utara, Provinsi Sulawesi Utara.

\section{METODE PENELITIAN}

\section{Waktu dan Lokasi Penelitian}

Penelitian ini dilakukan di hutan mangrove Desa Budo, Kecamatan Wori, Kabupaten Minahasa Utara, pada tanggal 14 Mei 2021 dengan posisi geografis $1^{\circ} 3741.82^{\prime \prime} \mathrm{N}$ dan 12452'58.16”E Gambar 1).

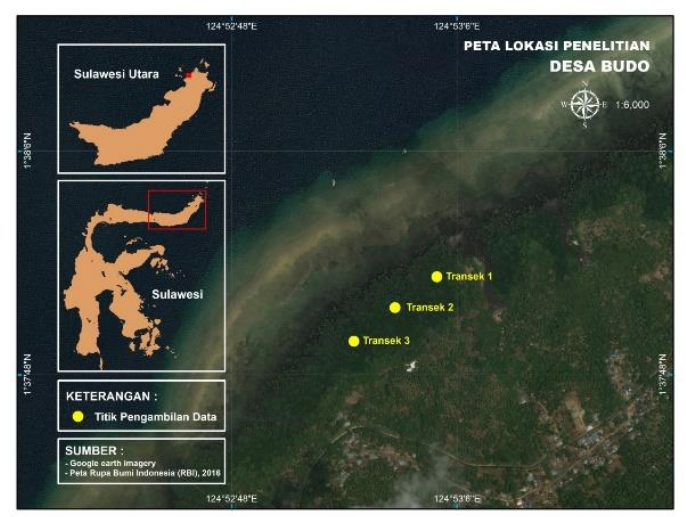

Gambar 1. Lokasi Penelitian (Desa Budo)

\section{Metode}

Metode yang digunakan dalam penelitian ini ialah metode transek garis. Teknik pengambilan data 
dilakukan dengan cara menarik garis lurus dari arah laut bagian vegetasi mangrove terluar ke arah darat di sepanjang hutan mangrove sampai berbatasan dengan tumbuhan/hutan daratan. Bentangan transek garis sepanjang $100 \mathrm{~m}$ diletakkan di 3 transek dimana tiap transek terdapat 5 plot atau petak kuadran berukuran $10 \mathrm{x}$ $10 \mathrm{~m}^{2}$ dengan jarak antar plot $20 \mathrm{~m}$ (English dkk., 1994)

Pengambilan data mangrove yang berada dalam plot diawali dengan melakukan identifikasi menggunakan buku panduan identifikasi mangrove Noor dkk., (2012), selanjutnya penghitungan jumlah pohon, pengukuran diameter setinggi dada $>4$ $\mathrm{cm}$ ) batang pohon mangrove setinggi dada atau sekitar 1,3 m.

\section{Analisis Data}

Untuk mengetahui kondisi mangrove dilakukan perhitungan sebagaimana dapat dilihat dibawah ini (Purba, 2013)

\section{Kerapatan Jenis (Di)}

$\mathbf{D i}=\frac{\text { Jumlah total individu } \mathrm{ke}-\mathrm{i}}{\text { luas total area pengamatan }}$

\section{Kerapatan Relatif Jenis (RDi)}

$\mathbf{R D i}=\frac{\text { jumlah total individu ke-i }}{\text { total tegakan seluruh jenis }} \times \mathbf{1 0 0}$

\section{Frekuensi Jenis (Fi)}

$\mathbf{F i}=\frac{\text { jumlah petak ditemukan suatu jenis }}{\text { jumlah total petak yang dibuat }}$

\section{Frekuensi Relatif Jenis (RCi)}

$\mathbf{R f i}=\frac{\text { jumlah jenis ke-i }}{\text { jumlah total petak yang dibuat }} \times 100$

\section{Penutupan Jenis (Ci)}

$\mathbf{C i}=\frac{\text { jumlah besar area DBH jenis }-\mathrm{i}}{\text { Luas total area pengambilan contoh }}$

\section{Penutupan Relatif Jenis (RCi)}

$\mathbf{R C i}=\frac{\text { tutupan relatif jenis ke-i }}{\text { tutupan total untuk seluruh jenis }} \times \mathbf{1 0 0}$

Indeks Nilai Penting (INP)

INP=RDi+RFi+Rci

Indeks Keanekaragaman Jenis (H')

$$
H^{\prime}=-\left(\sum \frac{n i}{N} \operatorname{Ln} \frac{n i}{N}\right)
$$

Keterangan :

$\mathrm{H}^{\prime}$ : Indeks diversitas Jenis

ni : Jumlah individu masing-masing jenis

$\mathrm{N}$ : Jumlah total individu semua jenis

\section{HASIL DAN PEMBAHASAN}

\section{Jenis-Jenis Mangrove}

Berdasarkan dengan hasil penelitian yang dilakukan di 3 stasiun ditemukan 3 spesies mangrove yaitu, Sonneratia alba, Rhizophora apiculata dan Bruguiera gymnorrhiza. Dari 3 spesies mangrove yang ditemukan, jenis $R$. apiculata adalah spesies yang dominan di hutan mangrove Desa Budo. Selain itu juga ditemukan diameter terbesar dimiliki oleh $R$. apiculata dengan ukuran diameter pohon sebesar $(1,75 \mathrm{~m})$. Menurut Kustanti (2011) R. apiculata merupakan salah satu spesies mangrove yang dominan di kawasan hutan mangrove karena mampu beradaptasi dengan baik pada lingkungannya bila dibandingkan dengan jenis lain.

\section{Struktur Komunitas Mangrove Kerapatan Jenis dan Kerapatan Relatif Jenis \\ Berdasarkan dengan hasil di} lapangan, nilai kerapatan jenis tertinggi pada transek 1 dimiliki oleh $R$. apiculata $0,05 \mathrm{ind} / \mathrm{m}^{2}$ dan terendah terdapat pada B. gymnorrhiza 0,01 
ind $/ \mathrm{m}^{2}$. Sedangkan untuk nilai kerapatan relatif jenis yaitu $67,57 \%$, dan 10,81\%. Pada transek 2 nilai kerapatan jenis tertinggi $R$. apiculata yaitu $0,03 \mathrm{ind} / \mathrm{m}^{2}$ dan nilai terendah dimiliki oleh $B$. gymnorrhiza dengan nilai $0,01 \mathrm{ind} / \mathrm{m}^{2}$. Untuk nilai kerapatan relatif jenis $51,61 \%$, dan $12,91 \%$. Selanjutnya untuk transek 3 nilai kerapatan jenis tertinggi $R$. apiculata dimiliki oleh 0,05 ind $/ \mathrm{m}^{2}$ dan nilai terendah terdapat pada $S$. alba 0,01 ind $/ \mathrm{m}^{2}$. Sedangkan untuk nilai kerapatan relatif jenis $63,16 \%$ dan 15,79\% (Gambar 2 dan 3). Menurut Kusmana (2010) tingginya kerapatan relatif dari jenis $R$. apiculata karena $R$. apiculata memiliki kawasan yang luas untuk hidup sehingga mampu berkembang selama masih mendapatkan suplai air asin. Tingginya nilai kerapatan jenis ditentukan oleh banyaknya jumlah individu, begitu pula sebaliknya jika jumlah individunya sedikit maka nilai kerapatannya rendah. (Agustini dkk., 2016; Paruntu., dkk 2017).

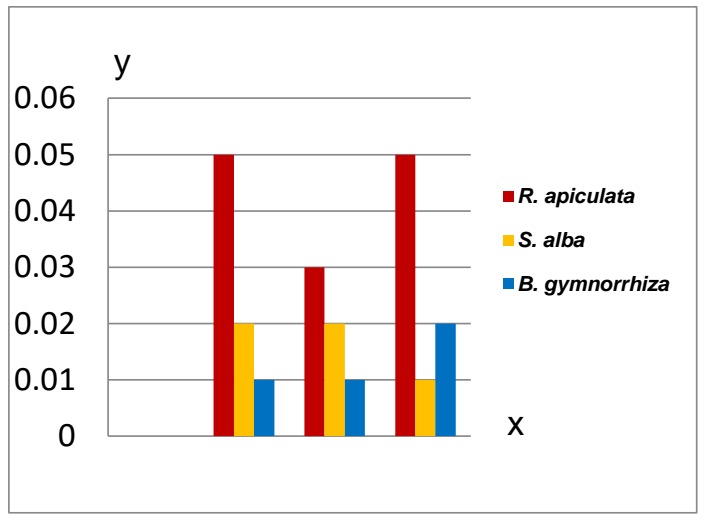

Gambar 2. Grafik kerapatan jenis, memperlihatkan jumlah distribusi pertumbuhan mangrove jenis $R$. apiculata S. alba dan B. gymnorrhiza pada transek 1, 2 dan 3

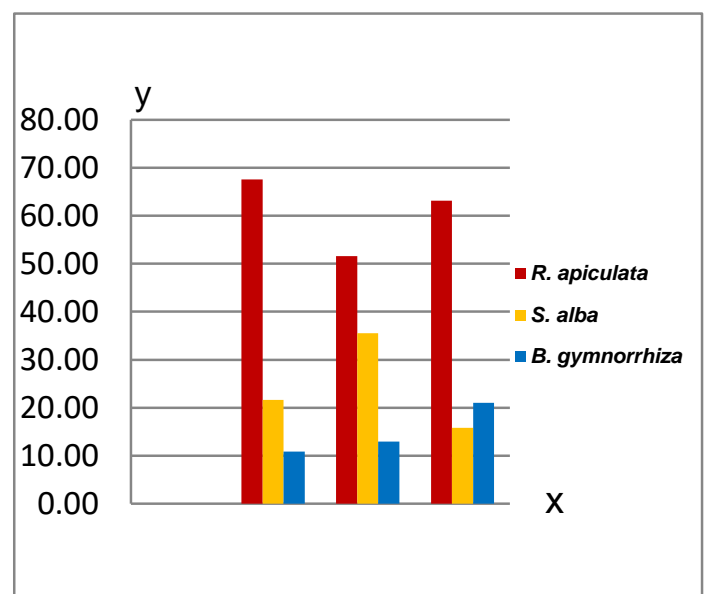

Gambar 3. Grafik kerapatan relatif jenis, memperlihatkan jumlah distribusi pertumbuhan mangrove jenis $R$. apiculata $S$. alba dan $B$. gymnorrhiza pada transek 1 , 2 dan 3

\section{Frekuensi Jenis dan Frekuensi Relatif Jenis}

Nilai tertinggi frekuensi jenis pada transek 1 terdapat pada $R$. apiculata yaitu 1,00 sedangkan nilai terendah dimiliki oleh B. gymnorrhiza yaitu 0,20 untuk nilai frekuensi relatif jenis yaitu $50,00 \%$, dan 10,00\%. Pada transek 2 nilai frekuensi jenis tertinggi dimiliki oleh $R$. apiculata yaitu 1.00 sedangkan terendah terdapat oleh $B$. gymnorrhiza yaitu 0,40 . Untuk nilai frekuensi relatif jenis $41,67 \%$, dan $16,66 \%$. transek 3 nilai frekuensi jenis tertinggi $R$. apiculata yaitu 1,00 sedangkan yang terendah dimiliki oleh $B$. gymnorrhiza 0,60 sedangkan untuk nilai frekuensi relatif jenis $45,45 \%$ dan $27,28 \%$. Frekuensi jenis tertinggi masih dimiliki $R$. apiculata pada setiap stasiun (Gambar 4 dan 5)

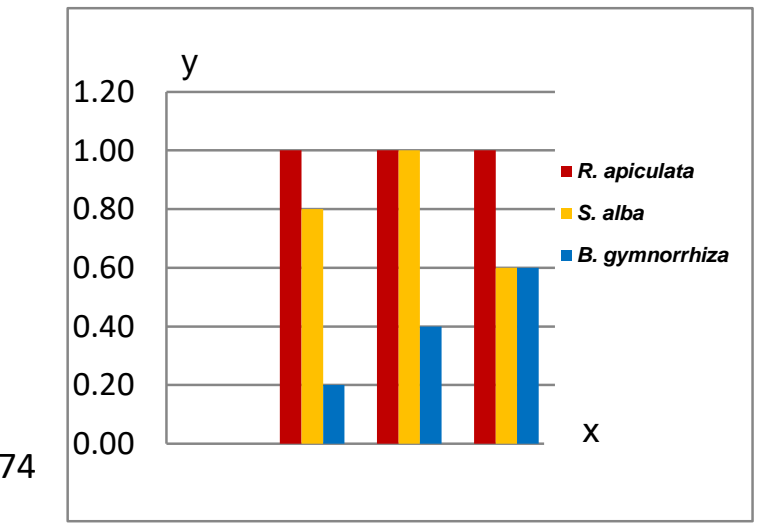


Gambar 4. Grafik frekuensi jenis, memperlihatkan jumlah distribusi pertumbuhan mangrove jenis $R$. apiculata S. alba dan B. gymnorrhiza pada transek 1, 2 dan 3

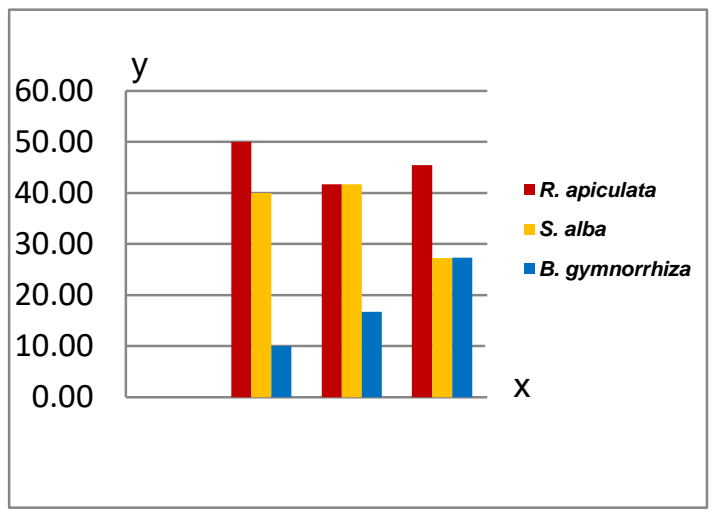

Gambar 5. Grafik frekuensi jenis, memperlihatkan jumlah distribusi pertumbuhan mangrove jenis $R$. apiculata S. alba dan B. gymnorrhiza pada transek 1, 2 dan 3

\section{Penutupan Jenis dan Penutupan Relatif Jenis}

Nilai penutupan jenis tertinggi pada transek 1 dimiliki oleh S.alba yaitu 16,18 , sedangkan nilai terendah B.gymnorrhiza memiliki nilai 2,13. Untuk nilai penutupan relatif jenis $74,64 \%$ dan $9,82 \%$. Untuk transek 2 nilai penutupan jenis tertinggi dimiliki oleh oleh S.alba yaitu 25,89. Sedangkan nilai terendah terdapat pada $R$. apiculata yaitu 6,26 . Untuk nilai penutupan relatif jenis $63,57 \%$ dan $15,37 \%$. Selanjutnya transek 3 nilai penutupan jenis tertinggi dimiliki oleh S.alba yaitu 10,73 sedangkan yang terendah terdapat pada $R$.apiculata memiliki 8,16 . Untuk nilai penutupan relatif jenisnya $38,32 \%$ dan
29,16\%. Dapat dilihat pada (Gambar 6 dan 7). Beberapa penelitian menunjukan bahwa nilai frekuensi dipengaruhi oleh nilai petak dimana ditemukannya spesies mangrove. Semakin banyak jumlah kuadran yang ditemukan jenis mangrove maka nilai frekuensi kehadiran jenis lebih tinggi (Fachrul, 2007). Nilai frekuensi mangrove dipengaruhi oleh banyaknya suatu jenis yang ditemukan pada setiap kuadran, makin banyak jumlah kuadran yang ditemukan jenis mangrove, maka nilai frekuensi kehadiran mangrove semakin tinggi (Babo dkk., 2020; Pandeirot $d k k$., 2020).

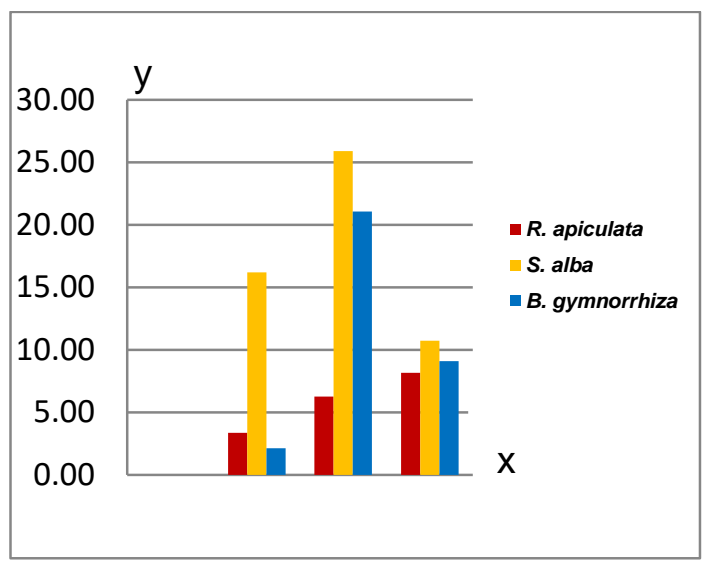

Gambar 6. Grafik penutupan jenis, memperlihatkan jumlah distribusi pertumbuhan mangrove jenis $R$. apiculata $S$. alba dan B. gymnorrhiza pada transek 1, 2 dan 3

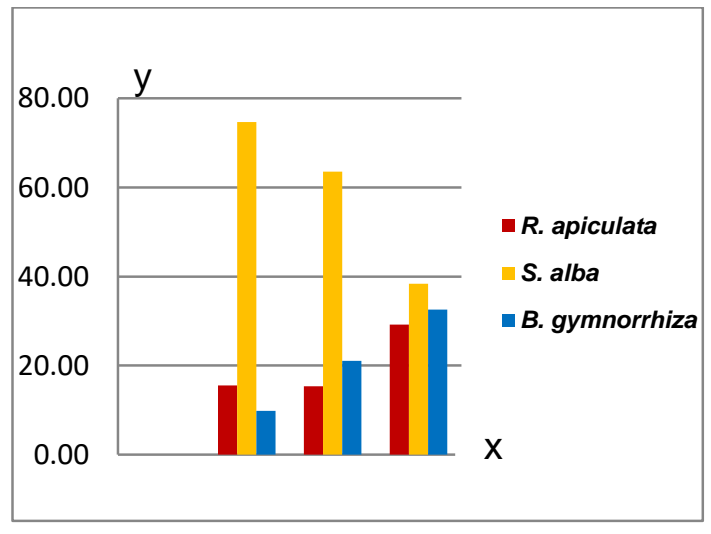

Gambar 7. Grafik penutupan relatif jenis, memperlihatkan jumlah 
distribusi pertumbuhan mangrove jenis $R$. apiculata $S$. alba dan B. gymnorrhiza pada transek 1, 2 dan 3

\section{Indeks Nilai Penting}

Indeks nilai penting tertinggi pada transek 1 dimiliki oleh $S$. alba yaitu 136,26 Sedangkan nilai terendah dimiliki oleh B. gymnorrhiza dengan nilai 30,63. Pada transek 2 indeks nilai penting tertinggi dimiliki $S$. alba dengan nilai 140,72 . dan nilai terendah terdapat pada $B$. gymnorrhiza 50,63. Selanjutnya transek 3 indeks nilai penting tertinggi dimiliki oleh jenis $R$. apiculata yaitu 137,77 sedangkan nilai terendah terdapat pada $B$. gymnorrhiza dengan nilai 80,84. (Gambar 8). Menurut Curtis dan Mc. Intosh (1950) dalam Kordi (2012) menyatakan sebuah indeks yang disebut INP sebagai jumlah dari kerapatan jenis, frekuensi jenis dan tutupan relatif yang dinyatakan dalam $\%$. Selanjutnya Agustini dkk, (2016) menambahkan bahwa spesies-spesies yang dominan dalam suatu komunitas tumbuhan akan memiliki indeks nilai penting yang tinggi, sehingga spesies yang paling dominan akan memiliki indeks nilai penting yang paling besar.

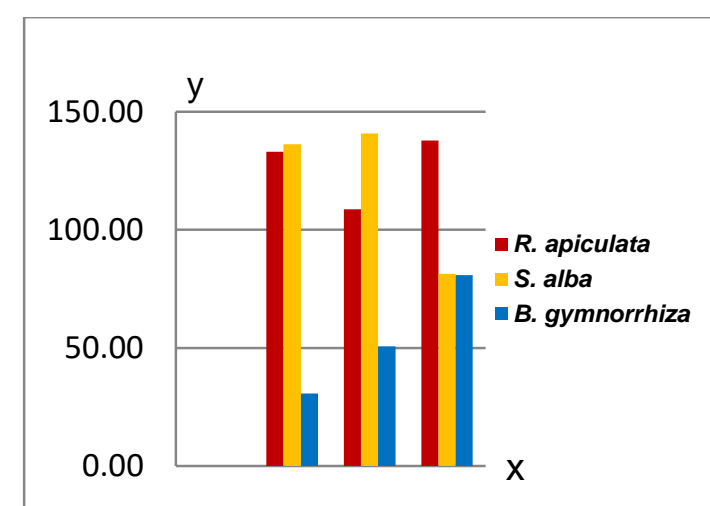

Gambar 8. Grafik indeks nilai penting, memperlihatkan jumlah distribusi pertumbuhan mangrove jenis $R$. apiculata S. alba dan B. gymnorrhiza pada transek 1,2 dan 3

\section{Indeks Keanekaragaman Jenis}

Nilai indeks keanekaragaman tertinggi terdapat pada transek 2 dengan nilai 0,97 sedangkan untuk nilai terendah dimiliki oleh transek 1 dengan nilai 0,84. Menurut Indriyanto (2006) Kanekaragaman spesies dapat menunjukan bahwa suatu komunitas memiliki kompleksitas tinggi karena interaksi spesies yang terjadi dalam komunitas itu sangat tinggi. Suatu komunitas dikatakan memiliki keanekaragaman spesies yang tinggi jika komunitas itu disusun oleh banyak spesies.

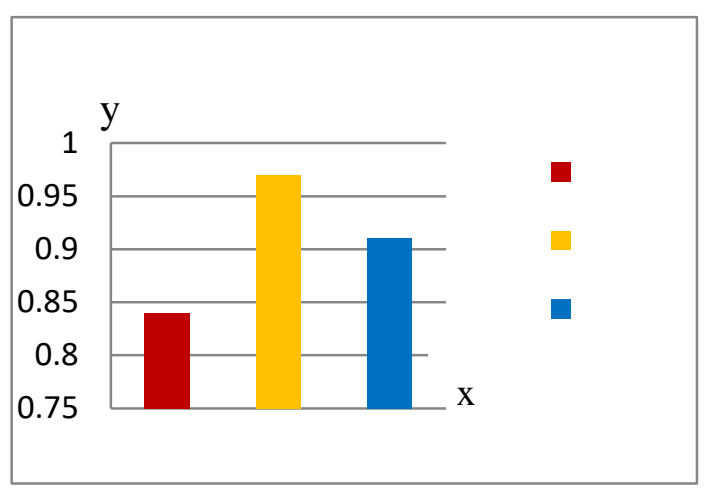

Gambar 9. Grafik keanekaragaman jenis, memperlihatkan jumlah distribusi pertumbuhan mangrove jenis $R$. apiculata S. alba dan B. gymnorrhiza pada transek 1,2 dan 3

KESIMPULAN

Berdasarkan hasil penelitian yang dilakukan di pesisir desa Budo ditemukan 3 spesies mangrove diantaranya, Rhizophora apiculata, Sonneratia alba dan Bruguiera gymnorrhiza. Dari hasil yang ditemukan $R$, apiculata merupakan spesies yang paling dominan di setiap transek dan dimiliki nilai kerapatan tertinggi pada ketiga transek.

\section{DAFTAR PUSTAKA}

Agustini, N. Tri., Ta'aladin, Z dan Purnama, D. 2016. Struktur Komunitas Mangrove Di Desa Kahyapu Pulau Enggano. Program Studi IImu Kelautan 
Fakultas Pertanian Universitas Bengkulu, Bengkulu. EISSN : 2527-5186 Jurnal Enggano Vol 1. No.1. 19-31.

Babo, P.P. Sondak, C.F.A. Paulus, J.J.H Schaduw, J.N.W. Angmalisang, P.A. Wantasen, A.S. 2020. Struktur Komunitas Mangrove Di Desa Bone Baru, Kecamatan Banggai Utara, Kabupaten Banggai Laut, Sulawesi Tengah. Jurnal Pesisir Dan Laut Tropis Vol 8 No. 2. 89.

Dahuri, R. 2003. Keanekaragaman Hayati Laut. Aset Pembangunan Berkelanjutan Indonesia. Penerbit PT Gramedia Pustaka Utama.

English. S. C. Wilkinson, V. Baker. Survey manual for tropical marine resources. ASEAN-Australia Marine Science Project: Living Coastal Resources.Australian Institute of Marine Science. Townsville, Australia.

Fachrul, M.F. 2007. Metode Sampling Bioekologi. Jakarta: Bumi Aksara.

Giri, C., Ochieng, E., Tieszen, L.L., Zhu, Z. Singh, A., Loveland, T., Duke, N. (2011). Status and distribution of mangrove forests of the world using earth observation satellite data. Global Ecology and Biogeography, 20 (1), 154-159.

Hayati, N.F., 2016. Profil Distribusi dan Kondisi Mangrove Berdasarkan Pasang Surut Air Laut Di Pulau Bangkobangkoang Kecamatan Liukang Tupabbiring Kabupaten Pangkep. Skripsi. Departemen IImu Kelautan Fakultas IImu Kelautan dan Perikanan Universitas Hasanuddin. Makassar.

Jacobs, R. Kusen, J,D. Sondak, C.F.A. Boneka, F.B. Warouw, V.
Mingkid, W.M. 2019. Struktur Komunitas Ekosistem Mangrove Dan Kepiting Bakau Di Desa Lamanggo Dan Desa Tope, Kecamatan Biaro, Kabupaten Kepulauan Siau, Tagulandang, Biaro. Program Studi IImu Kelautan, Fakultas Perikanan dan IImu Kelautan, Universitas Sam Ratulangi, Manado. Junal Pesisir dan Laut Tropis Vol. 1. No. 1.

Kordi, K.M.G.H. 2012. Ekosistem Mangrove : Potensi Fungsi dan Pengelolaannya. Rineka Cipta: Jakarta.

Kusen, J. D., Lumingas, L. J. L. \& Rondo, M. 2016. Ekologi Laut Tropis. Fakultas Perikanan dan IImu Kelautan. Universitas Sam Ratulangi Manado.

Kusmana, C. 2010. Respon Mangrove Terhadap Perubahan Iklim Global: Aspek Biologi dan Ekologi Mangrove. Makalah disajikan dalam Loka Karya Nasional Peran Mangrove dalam Mitigasi Bencana dan Perubahan Iklim, KKP, Jakarta 14-15.

Kustanti, A. 2011. Manajemen Hutan Mangrove. Bogor (ID). PT. Penerbit Institut Pertanian Bogor.

LIPI, 2014. Kekinian Keanekaragaman Hayati Indonesia 2014. LIPI Pres, anggota Ikapi. Pusat Penelitian Biologi.

Indriyanto, 2006. Ekologi Hutan. Jakarta: Bumi aksara.

Noor, Y. R., Khazali, M. dan Suryadiputra, I.N.N. 2012. Panduan Pengenalan Mangrove di Indonesia. Bogor.

Purba, R. 2013. Struktur Komunitas Ekosistem Mangrove di Pulau Poto Desa Kelong Kecamatan 


$\begin{array}{lcr}\text { Bintan } & \text { Pesisir } & \text { Kabupaten } \\ \text { Bintan } & \text { Provinsi } & \text { Kepulauan } \\ \text { Riau. } & \text { Skripsi. } & \text { Universitas } \\ \text { Maritim } & \text { Raja } & \text { Ali Haji, } \\ \text { Tanjungpinang. } & & \end{array}$

Pandeirot G L, Rumengan A P, Paruntu C $P$, Darwisito $S$, Ompi $M$, Wantasen A S. 2020. Analisis Struktur Komunitas Mangrove di Kawasan Sekitar PT. Conch Kabupaten Bolaang Mongondow. Jurnal Pesisir Dan Laut Tropis. 8.(2): 104-113.

Paruntu C, Windarto A, Rumengan A. 2017. Karakteristik Komunitas Mangrove Desa Motandoi Kecamatan Pinolosian Timur Kabupaten Bolaang Mongondow Selatan Provinsi Sulawesi Utara. Jurnal Pesisir dan Laut Tropis 5 (2), 53-65.

Rumengan A. P., Mantiri D. M. H., Rompas R., Hutahaean A., Kepel T. L., Paruntu C. P., Kepel R. C., Gerung G. S., 2018 Carbon stock assessment of mangrove ecosystem in Totok Bay, southeast Minahasa Regency, North Sulawesi, Indonesia. AACL Bioflux 11(4):1280-1288.

Sapsuha, J., Djamaluddin, R., Sondak, CFA., Rampengan, R.M., Opa, E.T., dan Kambey, A.D. 2018. Analisis tutupan vegetasi mangrove di Pulau Mantehage, Taman Nasional Bunaken, Sulawesi Utara. Jurnal Pesisir dan Laut Tropis 2(1): 37-44

Sondak, CFA. 2015. Estimasi potensi penyerapan karbon biru (blue carbon) oleh hutan mangrove Sulawesi Utara. Journal of Asean Studies on Maritime Issues 1(1): 24-29

Takarendehang, R., Sondak, C. F.A. Kaligis, E. Kumampung, D. Manembu, I. S. Unstain N.W.J.
Rembet Kondisi Ekologi Dan Nilai Manfaat Hutan Mangrove Di Desa Lansa, Kecamatan Wori, Kabupaten Minahasa Utara. Program Studi IImu Kelautan Fakultas Perikanan dan IImu Kelautan, Universitas Sam Ratulangi, Manado. Jurnal Pesisir dan Laut Tropis Vol. 6. No. 2.

Tidore, F., Sondak, C. F.A dan Rumengan, A. P. 2018. Estimasi kandungan karbon (C) pada serasah daun mangrove di Desa Lansa Kecamatan Wori Kabupaten Minahasa Utara. Jurnal Pesisir dan Laut Tropis Vol. 2. No. 1. Hal. 53-54.

Upara, U., Kusen, J.D. Sondak, C.F.A. Schaduw, J.N.W. Tilaar, S.O. Lasabuda, R. 2021. Struktur Komunitas Dan Zonasi Vegetasi Mangrove Desa Darunu Kecamatan Wori Kabupaten Minahasa Utara. Jurnal Pesisir Dan Laut Tropis. Vol. 9. No. 1. 